\title{
Internal mammary lymph node recurrence: rare but characteristic metastasis site in breast cancer
}

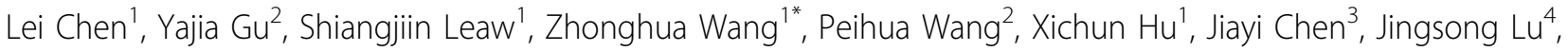 \\ Zhimin $\mathrm{Shao}^{4}$
}

\begin{abstract}
Background: To assess the frequency of IMLN recurrence, its associated risk factors with disease-free interval (DFI) and its predicting factors on overall survival time.

Methods: 133 cases of breast cancer IMLN recurrence were identified via the computerized CT reporting system between February 2003 and June 2008, during which chest CT for patients with breast cancer $(n=8867)$ were performed consecutively at Cancer Hospital, Fudan University, Shanghai, China. Patients' charts were retrieved and patients' characteristics, disease characteristics, and treatments after recurrence were collected for analysis. The frequency was 1.5\% (133/8867).

Results: IMLN recurrence was presented as the first metastatic site in 121 (91\%) patients while 88 (66.2\%) had other concurrent metastases. Typical chest CT images included swelling of the IMLN at the ipsilateral side with local lump and sternal erosion located mostly between the second and third intercostal space. The median disease-free interval (DFI) of IMLN recurrence was 38 months. The independent factors that could delay the IMLN recurrence were small tumor size (HR 0.5 95\%Cl: $0.4-0.8 ; p=0.002)$, and positive ER/PR disease (HR 0.6, 95\% Cl: $0.4-0.9 ; p=0.006$ ). The median survival time after IMLN recurrence was 42 months, with a 5 -year survival rate of $30 \%$. Univariate analysis showed four variables significantly influenced the survival time: DFI of IMLN recurrence $(p=0.001)$, no concurrent distant metastasis $(p=0.024)$, endocrine therapy for patients with positive ER/PR $(p=0.000)$, radiotherapy $(p=0.040)$. The independent factors that reduced the death risk were no concurrent distant metastases (HR: 0.7, 95\% Cl: $0.4-0.9 ; p=0.031$ ), endocrine therapy for patients with positive ER/PR status (HR: $0.2,95 \% \mathrm{Cl}: 0.1-0.5 ; p=0.001$ ) and palliative radiotherapy (HR: $0.3,95 \% \mathrm{Cl}: 0.1-0.9 ; p=0.026$ ).
\end{abstract}

Conclusions: The risk of IMLN recurrence is low and there are certain characteristics features on CT images. ER/PR status is both a risk factor for DFI of IMLN recurrence and a prognostic factor for overall survival after IMLN recurrence. Patients with only IMLN recurrence and/or local lesion have a good prognosis.

\section{Background}

The significance of internal mammary lymph node (IMLN) as a second lymph node basin in breast cancer where $8 \% \sim 37 \%$ tumors drain to IMLN while $1 \% \sim 5 \%$ of tumor exclusively drain to the IMLN had been recognized as a major prognostic factor historically [1-5]. It was reported that $54 \%$ of central and inner quadrant tumors and $18 \%$ lateral quadrant tumors were associated with positive IMLN while $44 \%$ of cases with positive axillary lymph nodes (ALN) had positive IMLN [6].

\footnotetext{
* Correspondence: zhonghuawang95@hotmail.com

'Department of Medical Oncology, Cancer Hospital of Fudan University,

Shanghai Medical College, Shanghai, PR China

Full list of author information is available at the end of the article
}

However, extended radical mastectomy that included removal of IMLN was abandoned in the 1970s, both as a staging procedure because of a low rate of IMLN metastases in the absence of concomitant ALN metastases, and as a therapeutic procedure because removal of all IMLN did not improve the prognosis. IMLN involvement was found to be $4 \%$ to $65 \%$ during surgery, $8 \%$ to $27 \%$ during sentinel node biopsy, and $13 \%$ to $37 \%$ on lymphoscintigraphy [1-5,7-10]. There was no local control or survival benefit comparing extended radical mastectomy (EM) to radical or modified radical mastectomy while more patients underwent EM experienced surgical trauma and pleura-related complications [11-14]. Yet, renewed interest has been observed for the 
untreated IMLN following the Early Breast Cancer Trialists' Collaborative Group (EBCTCG) meta-analysis that had established the importance of local-regional control on long- term survival [15].

Following surgery, systemic adjuvant chemotherapy is indicated in selected cases of localized disease based upon prognostic risk factors. All patients with hormone receptor-positive tumors should be considered for adjuvant endocrine therapy lasting for at least 5 years. Radiation of the chest wall and regional lymph nodes is suggested following mastectomy in selected high-risk patients. However, the value of IMLN irradiation without ignoring the risk of cardiac morbidity in the subset of patients with positive IMLN remains unclear presently while the prognostic significance of IMLN recurrences were scarce and controversial. Therefore, we undertake the initiative to review all the patients presented with IMLN recurrence at our institution in order to understand the characteristics associated with IMLN and its predicting influence on the prognosis of breast cancer so that we might have a better understanding in decision making for the most appropriate management for patients who had undergone radical or modified radical mastectomy. The aim of this study was to assess the chance of IMLN recurrence in a single institution, its associated risk factors with disease-free interval (DFI) and its predicting factors on overall survival time. A statistical analysis of a series of 133 breast cancer patients with IMLN recurrences is presented.

\section{Methods}

IMLN recurrence in our study was defined as a soft nodule with a diameter of $1 \mathrm{~cm}$ or larger adjacent to the internal mammary vessels within the first through sixth parasternal anterior intercostal space on spiral chest CT scan and/or confirmed by cytology. Surgical management usually performed at our center for patients with primary breast cancer included modified and radical mastectomy. Adjuvant chemotherapy for four to six cycles of cyclophosphamide, methotrexate, and 5-fluorouracil (CMF), cyclophosphamide, epirubicin, and 5fluorouracil (CEF) and CEF followed by docetaxel are usually given for patients with node-positive disease or at high risk despite having node-negative disease. Adjuvant radiotherapy at a dose of 45-50 Gy delivered to fields including chest wall and supraclavicular area with a 10-Gy boost to tumor bed using targeted fields of electrons are recommended for postmastectomy patients with primary tumor size greater than $5 \mathrm{~cm}, 4$ or more positive axillary lymph nodes, or positive pathologic margins. Adjuvant endocrine therapy was given for patients with ER/PR positive tumors while trastuzumab was not available for patients with HER-2 positive disease then. Patient was followed-up every 3 months after primary surgery with documented physical examination, every 6 months for ultrasonic examination, every 12 months for conventional CT-scan further spiral chest CT scan if indicated.

To identify patients with IMLN recurrence, we reviewed all chest spiral CT (computed tomographic) reports covering a 5-year span from Feb 2003 through June 2008 when CT reports were recorded by computer at Cancer Hospital of Fudan University, Shanghai, China, which served a population of almost half million. All CT examinations were performed using a 40-row helical CT scanner operated at $120 \mathrm{kV}$ and $100 \mathrm{mAs}$, with a maximized $45 \times 45 \mathrm{~cm}$ field of view, a $512 \times 512$ matrix, and the table speed of $1.53 \mathrm{~mm} / 0.5$ seconds (Somatom-40-row, Siemens Medical, Germany). CT images were obtained using consecutive $5 \mathrm{~mm}$-thick CT scanning from the supraclavicular region to the top of diaphragm with breath holding. Each CT scan which reported internal mammary lymph node enlargement was reviewed again by two radiologists for the confirmation of clinically apparent IMLN recurrence.

The frequency of IMLN recurrence in this series was $1.5 \%(133 / 8867)$ after radical $(\mathrm{n}=59)$ or modified radical mastectomy $(\mathrm{n}=74)$. The primary surgery time was between August 1988 and June 2007, the median surgery time was Mar 2003. Patients who received primary extended radical mastectomy were excluded from this study. IMLN status was not evaluated by sentinel LN biopsy.

The median age at surgery was 57 years, with 78 (58.6\%) patients being postmenopausal. The median primary tumor size was $2.5 \mathrm{~cm}$ (range: $1-7 \mathrm{~cm}$ ), among which $31.6 \%(\mathrm{n}=42)$ was $\leq 2 \mathrm{~cm}, 63.2 \%(\mathrm{n}=84)$ was between $2 \mathrm{~cm}$ to $5 \mathrm{~cm}$, and $5.2 \%(\mathrm{n}=7)>5 \mathrm{~cm}$. Number of ALN involvement was negative in $46.6 \%(n=62)$ patients, $1 \sim 3$ in $32.3 \%$ patients $(n=43)$, and $\geq 4$ in $21.1 \%$ patients $(\mathrm{n}=28)$. According to $6^{\text {th }}$ AJCC staging manual, 17 (12.8\%) patients had stage I, 89 (64.4\%) had stage II, and $29(21.8 \%)$ had stage III disease. 78 (58.6\%) patients were ER/PR positive. 29 (21.8\%) had HER-2 positive disease (HER-2 positive was defined as +++ by IHC method or FISH positive). The most common histological type was invasive ductal carcinoma, with $46 \%$ of the tumors located at the areola and inner quadrant area.

After primary surgery, 124 (93.2\%) patients received adjuvant chemotherapy. Only $15.8 \%(21 / 133)$ received adjuvant radiotherapy due to worrisome of the toxicity of radiotherapy. All patients with ER/PR positive tumors received adjuvant endocrine therapy (73 of 78 patients received tamoxifen $20 \mathrm{mg}$ daily, another 5 patients received aromatase inhibitor). The median follow-up time was 52 months (range: 10-246 months). All patients' characteristics were listed in Table 1. 
Table 1 Patient Characteristics

\begin{tabular}{|c|c|c|}
\hline \multirow[b]{2}{*}{ Characteristic } & \multicolumn{2}{|c|}{ Patients } \\
\hline & $\mathrm{N}$ & $\%$ \\
\hline \multicolumn{3}{|l|}{ Age (years) } \\
\hline Median (range) & \multicolumn{2}{|c|}{$47(23-72)$} \\
\hline \multicolumn{3}{|l|}{ Menopausal stastus } \\
\hline Premenopausal & 55 & 41.4 \\
\hline Postmenopausal & 78 & 58.6 \\
\hline \multicolumn{3}{|l|}{ Histologic type } \\
\hline Invasive ductal carcinoma & 125 & 94.0 \\
\hline Invasive lobular carcinoma & 5 & 3.8 \\
\hline Medullary carcinoma & 3 & 2.2 \\
\hline \multicolumn{3}{|l|}{ Primary tumor location } \\
\hline Areola and inner area & 61 & 45.9 \\
\hline Outer area & 72 & 54.1 \\
\hline \multicolumn{3}{|l|}{ Primary tumor size $(\mathrm{cm})$} \\
\hline Median (range) & \multicolumn{2}{|c|}{$2.5(1-7)$} \\
\hline$\leq 2$ & 42 & 31.6 \\
\hline$>2$ & 91 & 68.4 \\
\hline \multicolumn{3}{|l|}{ Anxillary lymph node (ALN) } \\
\hline negative & 62 & 46.6 \\
\hline positive & 71 & 53.4 \\
\hline \multicolumn{3}{|l|}{ TNM stage } \\
\hline$|-| \mid$ & 104 & 78.2 \\
\hline III & 29 & 21.8 \\
\hline \multicolumn{3}{|l|}{ ER/PR status } \\
\hline Positive & 78 & 58.6 \\
\hline Negative & 55 & 41.4 \\
\hline \multicolumn{3}{|l|}{ HER-2 status } \\
\hline Positive $^{\&}$ & 29 & 19.5 \\
\hline Negative & 104 & 80.5 \\
\hline \multicolumn{3}{|l|}{ Adjuvant chemotherapy } \\
\hline Yes & 124 & 93.2 \\
\hline No & 9 & 6.8 \\
\hline \multicolumn{3}{|l|}{ Adjuvant radiotherapy \# } \\
\hline Yes & 21 & 15.8 \\
\hline No & 112 & 48.2 \\
\hline
\end{tabular}

\&HER-2 positive was defined as +++ by IHC method and/or FISH positive. \#Adjuvant radiotherapy field included chest wall and supraclavicular area, and 10-Gy boost was delivered to the tumor bed

$90 \%$ patients were followed as planned while $10 \%$ present with recurrent disease at a more serious condition due to poor compliance. All 133 patients were evaluated for distant metastases using abdominal CT/MRI and bone scan after the diagnosis of IMLN recurrence. The types of therapy right after IMLN recurrence were recorded. Endocrine therapy was most commonly used for patients with ER/PR positive disease or at low risk of rapidly progressive disease. Patient with ER and PR negative, life-threaten condition or multiple metastatic sites often received chemotherapy. Radiotherapy was given either as initial or palliative treatment based on patients' disease presentation.

DFI of IMLN recurrence was calculated from the primary surgery to IMLN recurrence. The overall survival time was calculated from the IMLN recurrence until death or last follow-up. Actuarial curves were compared by the two-tailed log-rank test and difference of $\mathrm{p} \leq$ 0.05 was considered significant. The independent prognostic significance of variables on the events and survival, proved to be significant factor in univariate analysis, was tested in proportional hazards regression models described by Cox. Survival analysis was carried out using life-table and Kaplan-Meier method. The estimates of the models are given as hazard ratio (HR) with 95\% confidence intervals (95\% CI).

Written informed consent was obtained from all patients at the time of admission. The study had been approved by the Fudan University Cancer Hospital Ethic Committee for Clinical Investigation. Patients' charts were retrieved and patients' characteristics, disease characteristics, and initial treatments after IMLN recurrence and patients' survival were collected for analysis.

\section{Results \\ Characteristics of IMLN recurrences Clinical characteristics}

Among the 133 patients, IMLN recurrence was presented as the first metastatic site in 121 (91.0\%) patients, only 12 had other sites of metastases prior to IMLN recurrence. 88 (66.2\%) patients had other concurrent metastasis sites, 45 patients had isolated IMLN recurrence, of whom 23 developed distant metastases later. There were 48 cases $(36.1 \%)$ with ipsilateral visible soft tissue mass beside the sternum, among which cytology examination had been presented for 33 patients, all confirmed recurrence. There were 20 (15.0\%) cases with localized skin involvement with painful presentation.

\section{Imaging of chest spiral CT scan}

The typical CT-scan presentation was enlargement and swelling of IMLN located on the ipsilateral side with the formation of a local lump and sternal erosion (Figure 1). Median enlarged nodal size was $2.5 \mathrm{~cm}$ (range: 1.0-9.0 $\mathrm{cm}$ ). The majority of the cases presented with lymphadenopathy traversing one to two anterior intercostal spaces, being $48.1 \%$ and, $33.9 \%$, respectively. Most nodal enlargement was located at the second and third intercoastal space, being $67.7 \%$ and $19.5 \%$, respectively. Isolated lymphadenopathy in the fifth spaces was not observed. About half of the cases with IMLN recurrence occurred at multiple levels and were most common in the second or third intercoastal spaces. Sternal erosion occurs in $64.7 \%$ patients. The characteristics of the imaging findings were presented in Table 2. 


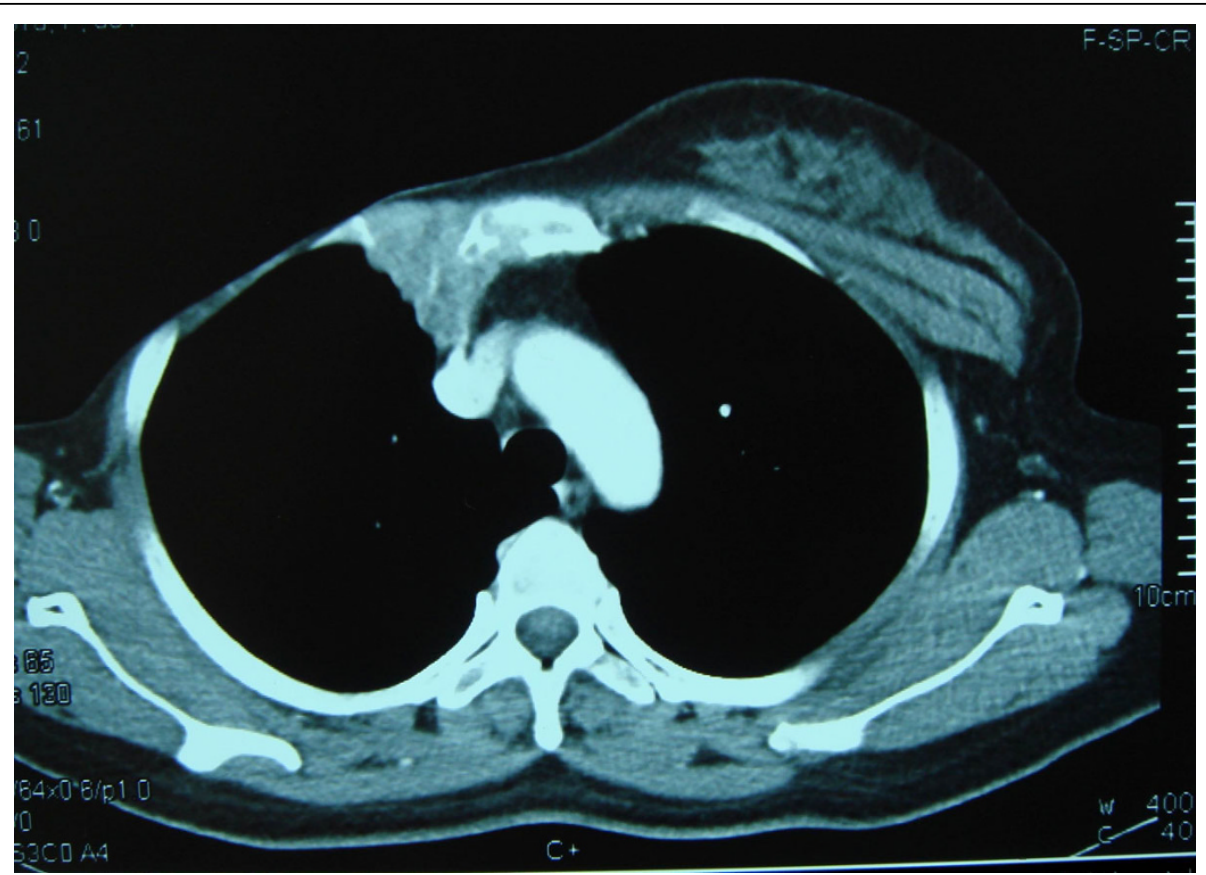

Figure $1 \mathrm{CT}$ image demonstrated internal mammary node forming a mass with a diameter of $3 \mathrm{~cm}$ at a level of the second right anterior intercostal space accompany by sternal erosion.

\section{Risk Factor of DFI for IMLN recurrence}

The median DFI of IMLN recurrence was 38 months (range: 4-241 months). Tumor size, ER/PR status, adjuvant radiotherapy for $\mathrm{T}>5 \mathrm{~cm}$ were variables that significantly influenced the DFI of IMLN recurrence (Table $3)$. The DFI for patients with primary tumor size $\leq 2$ $\mathrm{cm}$ and $>2 \mathrm{~cm}$ was 49 and 33 months, respectively ( $\mathrm{p}=$ 0.021 ). The DFI for patients with positive and negative ER/PR was 50 and 32 months, respectively $(\mathrm{p}=0.020)$. For patients with $\mathrm{T}>5 \mathrm{~cm}$, DFI was 56 months and 21 months for those with or without adjuvant radiotherapy, respectively $\mathrm{p}=0.018$. All the following tested variables had no influence on the DFI of IMLN recurrence: menopausal status, primary tumor location, number of ALN involvement, post-surgery TNM stage, HER-2 status, adjuvant chemotherapy, adjuvant radiotherapy for $\geq$ 4 positive ALN.

Three factors were tested in multivariate analysis: tumor size, ER/PR status, adjuvant radiotherapy for $\mathrm{T}$ $>5 \mathrm{~cm}$. The result showed that the DFI of IMLN recurrence was independently influenced by tumor size (HR 0.5, 95\% CI: $0.4-0.8 ; \mathrm{p}=0.002$ ), and ER/PR status (HR 0.6, 95\% CI: $0.4-0.9 ; \mathrm{p}=0.006)($ Table 3 ).

\section{Prognostic factor after IMLN recurrence}

The median survival time after IMLN recurrence was 42 months, and the 5 -year survival rate was $30 \%$ for all patients. The 5-year survival of patients without concurrent other sites metastasis was $43 \%$. The results of univariate analysis of the tested prognostic variables are shown in Table 4. After univariate analysis, four predicting variables significantly influenced the survival time. DFI of IMLN recurrence $(<2$ years vs $\geq 2$ years, $\mathrm{p}=$ 0.001 ), concurrent metastasis (none and local vs distant metastases, $\mathrm{p}=0.024$ ), endocrine therapy for patients with positive ER/PR (yes vs no, $\mathrm{p}=0.000$ ), radiotherapy (yes vs no, $\mathrm{p}=0.040$ ). Whether IMLN presented as first or subsequent metastatic site, the size of recurrent IMLN and the type of first-line chemotherapy had no influence on the overall survival time. The median overall survival time for patients with isolated IMLN recurrence was 63 months, patients with concurrent local metastasis 51 months $(\mathrm{p}=0.432)$. The median overall survival time when both isolated IMLN and with local metastases was combined was 61 months, while that of concurrent bone or visceral metastasis (lung or liver or brain, etc) was 32 months. Univariate analysis also showed that the presence of concurrent distant metastases $(\mathrm{p}=0.010)$ predicted the survival time (Table 4$)$.

The four factors proved to be significant in univariate analysis were tested by multivariate analysis (shown in Table 4). The following independent factors that reduced the risk of death were no concurrent distant metastases (HR: 0.7, 95\% CI: 0.4- 0.9; $p=0.031$ ), presence of endocrine therapy for patients with positive ER/PR (HR: 0.2, 95\% CI: $0.1-0.5 ; p=0.001$ ), presence of sequential radiotherapy delivered to the IMLN area (HR: 0.3, 95\% CI: 0.1- 0.9; $p=0.026$ ). 
Table 2 Characteristics of IMLN Recurrence

\begin{tabular}{|c|c|c|}
\hline & $\mathrm{N}$ & $\%$ \\
\hline \multicolumn{3}{|l|}{ Clinical } \\
\hline \multicolumn{3}{|c|}{ As first site of metastasis } \\
\hline Yes & 121 & 91 \\
\hline No & 12 & 9 \\
\hline \multicolumn{3}{|c|}{ Concurrent other sites metastasis } \\
\hline Yes & 88 & 66.2 \\
\hline No & 45 & 33.8 \\
\hline \multicolumn{3}{|c|}{ Visible soft tissue mass beside the sternum } \\
\hline Yes & 42 & 31.6 \\
\hline No & 91 & 68.4 \\
\hline \multicolumn{3}{|c|}{ Local pain and skin involvement } \\
\hline Yes & 20 & 15.0 \\
\hline No & 113 & 85.0 \\
\hline \multicolumn{3}{|l|}{ Imaging of $C T$ scan } \\
\hline \multicolumn{3}{|c|}{ Size of IMLN recurrence $(\mathrm{cm})$} \\
\hline Median (range) & $2.5(1-9)$ & \\
\hline \multicolumn{3}{|c|}{ Anterior intercostal space } \\
\hline One & 64 & 48.1 \\
\hline Two & 45 & 33.9 \\
\hline Three & 19 & 14.3 \\
\hline Four & 5 & 3.7 \\
\hline \multicolumn{3}{|c|}{ Dominant location anterior intercostal space } \\
\hline First & 15 & 11.3 \\
\hline Second & 90 & 67.7 \\
\hline Third & 26 & 19.5 \\
\hline Forth & 2 & 1.5 \\
\hline \multicolumn{3}{|l|}{ Sternal erosion } \\
\hline Yes & 86 & 64.7 \\
\hline No & 47 & 35.3 \\
\hline
\end{tabular}

\section{Discussion}

This is the largest report of IMLN recurrences up to date. The frequency of IMLN recurrence was rare $[16,17], 1.5 \%$ in our series, and even rarer among patients with other cancer types. But it was characteristic recurrence site for the patients with breast cancer, only two patients with other solid tumors, both male, were noted to have IMLN metastases on CT scan in our institution, one suffered from malignant melanoma, and the other rhabdomyosarcoma. Two independent factors were found to delay IMLN recurrence among patients with breast cancer: small tumor size, and positive ER and PR status. Three independent factors were identified to increase death risk: absence of endocrine therapy for patients with positive ER/PR status, absence of palliative radiotherapy and concurrent distant metastases.

The diagnosis of IMLN recurrence was based on the clinical presentation and chest CT-scan [18]. Clinical symptoms may include broad base parasternal swelling with concomitant pain or skin involvement. Some patients with IMLN recurrence were discovered on a chest CT-scan during routine follow-up. The typical CT-scan presentation was swelling of IMLN, usually located at the ipsilateral side of the treated breast, with a local lump and sternal erosion. About half of the IMLN recurrence occured at multiple levels and were most commonly seen in the second or third intercoastal space. Most IMLN recurrence, $66.2 \%$ in this series, presented concurrently with other metastases sites, or were followed by visceral metastasis similar to those of other reports [19]. Therefore, once IMLN recurrence was detected, a thorough re-staging workup was necessary to evaluate the extent of the disease status.

Recurrence in the IMLN is rare, despite the fact that these nodes are the second LN drainage basin of breast cancer and are left untreated after surgery in most patients. Tumor location, positive ALN, younger age, and larger tumor size $(>5 \mathrm{~cm})$ had been reported as high risk factors of tumor cells drainage to IMLN [8], but the risk factors of IMLN recurrence had not been clarified. Tumor size has been reported as a risk factor not only for IMLN drainage but also for local recurrence $[8,19,20]$. Harris et al reported T2 tumor size $(P=$ $0.004)$, and Stage II disease $(P=0.017)$ were associated significantly with any regional lymph node recurrence (including ALN, IMLN, supraclavicular lymph node). Bijker et al reported the significant independent factors were tumor size $>5 \mathrm{~cm}$ (measured by pathology) ( $\mathrm{p}=$ 0.0002). Conflicting results have been reported regarding the influence of ALN status on regional recurrence $[19,20]$. Since all patients in our present study had developed IMLN recurrence, factors that could influence the DFI of IMLN recurrence instead of risk factors for IMLN recurrence were evaluated. We concluded that tumor size, not ALN status, could influence the interval of IMLN recurrence.

Several studies reported that adjuvant treatment modalities did not influence the risk of local recurrence after breast-conserving surgery for early-stage disease [21-23]. However, adjuvant hormonal therapy was observed to delay IMLN recurrence for patients with ER/PR positive disease in our study. We postulated that different surgical methods and stage at presentation in our series may contribute to the different conclusion. The finding in our series that adjuvant radiotherapy could significant delay the IMLN recurrence for patients with tumor size $>5 \mathrm{~cm}$, paralleled other studies on postmastectomy radiation delivered to fields including IMLN, supraclavicular, axillary, and chest wall, which demonstrated significant decreased risk of locoregional recurrence in high-risk breast cancer patients [24,25]. The significance of adjuvant chemotherapy for delayed IMLN recurrence could not be demonstrated in our study due to the fact that the majority of patients included in this analysis received adjuvant chemotherapy per NCCN guidelines. 
Table 3 Univariate and multivariate analysis of DFI for IMLN recurrence

\begin{tabular}{|c|c|c|c|c|c|c|}
\hline \multirow[t]{2}{*}{ Factors } & \multirow[t]{2}{*}{$\mathbf{N}$} & \multicolumn{2}{|c|}{ Univariate analysis } & \multicolumn{3}{|c|}{ Multivariate analysis } \\
\hline & & Median (m) & $p$-value & HR & $95 \% \mathrm{Cl}$ & $p$-value \\
\hline Menopausal stastus & & & 0.773 & & NS & \\
\hline Premenopausal & 55 & 33 & & & & \\
\hline Postmenopausal & 78 & 42 & & & & \\
\hline Primary tumor location & & & 0.837 & & NS & \\
\hline Areola and inner area & 61 & 38 & & & & \\
\hline Outer area & 72 & 40 & & & & \\
\hline Tumor size $(\mathrm{cm})$ & & & $0.008^{*}$ & 0.5 & $0.4-0.8$ & $0.002^{*}$ \\
\hline$\leq 2$ & 42 & 49 & & & & \\
\hline$>2$ & 91 & 33 & & & & \\
\hline Axillary lymph node & & & 0.070 & & NS & \\
\hline negative & 62 & 43 & & & & \\
\hline positive & 71 & 33 & & & & \\
\hline TNM stage & & & 0.390 & & NS & \\
\hline $\mid-\|$ & 104 & 38 & & & & \\
\hline III & 29 & 29 & & & & \\
\hline ER/PR status & & & $0.020^{*}$ & 0.6 & $0.4-0.9$ & $0.006^{*}$ \\
\hline Positive & 78 & 50 & & & & \\
\hline Negative & 55 & 32 & & & & \\
\hline HER-2 status & & & 0.193 & & NS & \\
\hline Positive & 29 & 26 & & & & \\
\hline Negative & 104 & 42 & & & & \\
\hline Adjuvant chemotherapy & & & 0.113 & & NS & \\
\hline Yes & 124 & 36 & & & & \\
\hline No & 9 & 41 & & & & \\
\hline Adjuvant radiotherapy for $T>5 \mathrm{~cm}$ & & & $0.018^{*}$ & 0.9 & $0.6-1.3$ & 0.463 \\
\hline Yes & 3 & 56 & & & & \\
\hline No & 4 & 21 & & & & \\
\hline Adjuvant radiotherapy for $A L N \geq 4$ & & & 0.949 & & NS & \\
\hline Yes & 20 & 29 & & & & \\
\hline No & 8 & 26 & & & & \\
\hline
\end{tabular}

The 5 -year survival rate of the 133 patients was $30 \%$ while that for those with isolated IMLN recurrence was $43 \%$. The results is similar to the findings of other studies on isolated local recurrence (IRL) of breast cancer, ranging from $39-84 \%$, IRL defined as new breast tumor, chest wall recurrence, overlying skin recurrence, supraclavicular recurrence [21,26-29]. Since isolated IMLN recurrence, longer DFI to IMLN recurrence, endocrine therapy and radiotherapy were four favorable prognostic factors for overall survival time, we propose that IMLN recurrence should be included in the definition for ILR.

Time to ILR, the most frequently reported prognostic factor for survival after local recurrence post breast-conserving surgery was also reported in our study for IMLN recurrence after radical or modified radical breast cancer surgery [28-30]. Endocrine therapy and radiotherapy could prolong the survival time dramatically but the benefit of chemotherapy was not observed in this study. This may be due to the fact that patients indicated for initial chemotherapy had a more advanced disease condition accompanying IMLN recurrence. However, due to the rarity of IMLN recurrence, it seemed difficult to initiate a prospective clinical trial to evaluate the influence of systemic treatment and radiotherapy on the survival.

The 2008 National Comprehensive Cancer Network Clinical Practice Guidelines recommend consideration of radiation therapy to internal mammary nodes for patients with node-positive breast cancer after mastectomy or breast-conserving surgery, noting "substantial controversy" on this topic. But as isolated IMLN recurrence is rare, it is unlikely that parasternal irradiation will result in a significant reduction of the risk of clinically apparent IMLN recurrence, based on the negligible risk of IMLN recurrence without adjuvant radiotherapy. Thus, we strongly advocate that if IMLN is clinical or 
Table 4 Univariate and multivariate analysis of survival time after IMLN recurrence

\begin{tabular}{|c|c|c|c|c|c|c|}
\hline \multirow[t]{2}{*}{ Factors } & \multirow[t]{2}{*}{$\mathbf{N}$} & \multicolumn{2}{|c|}{ Univariate analysis } & \multicolumn{3}{|c|}{ Multivariate analysis } \\
\hline & & Median (m) & $p$-value & HR & $95 \% \mathrm{Cl}$ & $p$-value \\
\hline As first site of metastasis & & & 0.407 & & NS & \\
\hline Yes & 121 & 34 & & & & \\
\hline No & 12 & 64 & & & & \\
\hline Size of IMLN & & & 0.984 & & NS & \\
\hline$\leq 4 \mathrm{~cm}$ & 116 & 51 & & & & \\
\hline$>4 \mathrm{~cm}$ & 17 & 38 & & & & \\
\hline DFI of IMLN recurrence & & & $0.001^{*}$ & 1.4 & $0.7-2.9$ & 0.342 \\
\hline$<2 \mathrm{y}$ & 44 & 31 & & & & \\
\hline$\geq 2 y$ & 89 & 63 & & & & \\
\hline Concurrent metastasis & & & $0.024^{*}$ & 0.7 & $0.4-0.9$ & $0.031^{*}$ \\
\hline No and local & 73 & 61 & & & & \\
\hline Visceral or bone & 60 & 32 & & & & \\
\hline Endocrine therpay & & & $0.000^{*}$ & 0.2 & $0.1-0.5$ & $0.001^{*}$ \\
\hline Yes & 54 & 78 & & & & \\
\hline No & 24 & 26 & & & & \\
\hline Chemotherapy & & & 0.078 & & NS & \\
\hline Yes & 72 & 34 & & & & \\
\hline No & 61 & 62 & & & & \\
\hline Radiotherapy $y^{\&}$ & & & $0.04^{*}$ & 0.3 & $0.1-0.9$ & $0.026^{*}$ \\
\hline Yes & 59 & 63 & & & & \\
\hline No & 74 & 32 & & & & \\
\hline
\end{tabular}

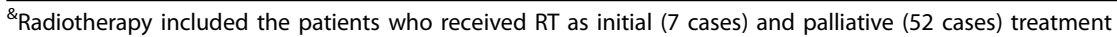

${ }^{*} p<0.05$

pathological negative, it should be left untreated regardless of the status of axillary nodes.

\section{Conclusions}

In conclusion, our data show that the risk of IMLN recurrence is low and there are certain characteristics features on CT images. ER/PR status is both a risk factor for DFI of IMLN recurrence and a prognostic factor for overall survival after IMLN recurrence. Patients with only IMLN recurrence and/or local lesion have a good prognosis.

\section{Acknowledgements}

We thank Dr. Jin Li for general support. We acknowledge our volunteers for participating in this retrospective analysis.

\section{Author details}

'Department of Medical Oncology, Cancer Hospital of Fudan University, Shanghai Medical College, Shanghai, PR China. ${ }^{2}$ Department of Diagnostic Radiology, Cancer Hospital of Fudan University, Shanghai Medical College, Shanghai, PR China. ${ }^{3}$ Department of Radiation Oncology, Cancer Hospital of Fudan University, Shanghai Medical College, Shanghai, PR China.

${ }^{4}$ Department of Breast Surgery, Cancer Hospital of Fudan University,

Shanghai Medical College, Shanghai, PR China.

\section{Authors' contributions}

LC participated in acquisition of data, analysis and interpretation of data, and drafting of the manuscript. YG and PW confirmed chest spiral CT. SL revised the manuscript. XH, JC, JL and ZS participated in acquisition of data. ZW conceived of the study, participated in its design and coordination and revised the final manuscript. All authors have read and approved the final manuscript.

\section{Competing interests}

The authors, their immediate families of this paper have no potential conflict of interest to disclose.

Received: 18 January 2010 Accepted: 7 September 2010

Published: 7 September 2010

\section{References}

1. Byrd DR, Dunnwald LK, Mankoff DA, Anderson BO, Moe RE, Yeung RS, Schubert EK, Eary JF: Internal mammary lymph node drainage patterns in patients with breast cancer documented by breast lymphoscintigraphy. Ann Surg Oncol 2000, 8:234-240.

2. Lamonica D, Edge SB, Hurd T, Proulx G, Stomper PC: Mammographic and clinical predictors of drainage patterns in breast lymphoscintigrams obtained during sentinel node procedures. Clin Nucl Med 2003, 7:558-564.

3. Van der Ent FW, Kengen RA, van der Pol HA, Povel JA, Stroeken HJ, Hoofwijk AG: Halsted revisited: internal mammary sentinel lymph node biopsy in breast cancer. Ann Surg 2001, 234:79-84.

4. Estourgie SH, Tanis PJ, Nieweg OE, Valdes Olmos RA, Rutgers EJ, Kroon BB: Should the hunt for internal mammary chain sentinel nodes begin? An evaluation of 150 breast cancer patients. Ann Surg Oncol 2003, 10:935-941.

5. Madsen E, Gobardhan P, Bongers V, Albregts M, Burgmans J, De Hooge P, Van Gorp J, van Dalen T: The impact on post-surgical treatment of sentinel lymph node biopsy of internal mammary lymph nodes in patients with breast cancer. Ann Surg Oncol 2007, 14:1486-1492.

6. Handley RS, Thackray AC: Invasion of internal mammary lymph nodes in carcinoma of the breast. Br Med J 1954, 1:61-63.

7. Donegan WL: The influence of untreated internal mammary metastases upon the course of mammary cancer. Cancer 1977, 39:533-538. 
8. Huang O, Wang L, Shen K, Lin H, Hu Z, Liu G, Wu J, Lu J, Shao Z, Han Q, Shen Z: Breast cancer subpopulation with high risk of internal mammary lymph nodes metastasis: analysis of 2,269 Chinese breast cancer patients treated with extended radical mastectomy. Breast Cancer Research and Treatment 2008, 107:379-387.

9. Urban JA, Marjani MA: Significance of internal mammary lymph node metastases in breast cancer. Am J Roentgenol Radium Ther Nucl Med 1971, 111:130-136.

10. Lacour J, Bucalossi P, Cacers E, Jacobelli G, Koszarowski T, Le M, RumeauRouquette $C$, Veronesi U: Radical mastectomy versus radical mastectomy plus internal mammary dissection: Five-year results of an international cooperative study. Cancer 1976, 37:206-214.

11. Lacour J, Le MG, Hill C, Kramar A, Contesso G, Sarrazin D: Is it useful to remove internal mammary nodes in operable breast cancer? Eur J Surg Oncol 1987, 13:309-314.

12. Veronesi $U$, Valagussa $P$ : Inefficacy of internal mammary nodes dissection in breast cancer surgery. Cancer 1981, 47:170-175.

13. Veronesi U, Marubini E, Mariani L, Valagussa P, Zucali R: The dissection of internal mammary nodes does not improve the survival of breast cancer patients: 30- year results of a randomised trial. Eur J Cancer 1999, 35:1320-1325

14. Klauber-DeMore N, Bevilacqua JL, Van Zee K, Borgen P, Cody HS: Comprehensive review of the management of internal mammary lymph node metastases in breast cancer. J Am Coll Surg 2001, 193:547-555.

15. Chen RC, Lin NU, Golshan M, Harris JR, Bellon JR: Internal mammary nodes in breast cancer: diagnosis and implications for patient management - a systematic review. J Clin Oncol 2008, 26:4981-4989.

16. Fowble B, Solin LJ, Schultz DJ, Goodman RL: Frequency, sites of relapse, and outcome of regional node failures following conservative surgery and radiation for early breast cancer. Int J Radiat Oncol Biol Phys 1989, 17:703-710.

17. Cranenbroek S, van der Sangen MJ, Kuijt GP, Voogd AC: Diagnosis, treatment and prognosis of internal mammary lymph node recurrence in breast cancer patients. Breast Cancer Research and Treatment 2005, 89:271-275.

18. Scott WW Jr, Fishman EK: Detection of internal mammary lymph node enlargement: comparison of CT scans and conventional roentgenogarms. Clincial Imaging 1991, 15:268-272.

19. Harris EE, Hwang WT, Seyednejad F, Solin LJ: Prognosis after Regional Lymph Node Recurrence in Patients with Stage I-II Breast Carcinoma Treated with Breast Conservation Therapy. Cancer 2003, 98:2144-2151.

20. Bijker N, Rutgers EJ, Peterse JL, van Dongen JA, Hart AA, Borger JH, Kroon BB: Low risk of locoregional recurrence of primary breast carcinoma after treatment with a modification of the Halsted radical mastectomy and selective use of radiotherapy. Cancer 1999, 85:1773-1781

21. Touboul E, Buffat $L$, Belkacémi $Y$, Lefranc JP, Uzan S, Lhuillier $P$, Faivre $C$ Huart J, Lotz JP, Antoine M, Pène F, Blondon J, Izrael V, Laugier A, Schlienger M, Housset M: Local recurrence and distant metastasis after breast-conserving surgery and radiation therapy for early breast cancer. Int J Radiation Oncology Biol Phys 1999, 43:25-38

22. Fisher B, Constantino J, Redmond C, Poisson R, Bowman D, Couture J, Dimitrov NV, Wolmark N, Wickerham DL, Fisher ER, et al: A randomized clinical trial evaluating tamoxifen in the treatment of patients with node-negative breast cancer who have estrogen-receptor positive tumors. N Engl J Med 1989, 320:479-484.

23. Fisher B, Redmond C, Dimitrov NV, Bowman D, Legault-Poisson S, Wickerham DL, Wolmark N, Fisher E, Margolese R, Sutherland C, et al: A randomized clinical trial evaluating sequantial methotrexate and fluorouracil in treatment of patients with node-negative breast cancer who have estrogen receptor negative tumors. N Engl J Med 1989, 320:473-478.

24. Overgaard M, Jensen MB, Overgaard J, Hansen PS, Rose C, Andersson M, Kamby C, Kjaer M, Gadeberg CC, Rasmussen BB, Blichert-Toft M, Mouridsen HT: Postoperative radiotherapy in high-risk postmenopausal breast-cancer patients given adjuvant tamoxifen: Danish Breast Cancer Cooperative Group DBCG 82c randomized trial [see comments]. Lancet 1999, 353:1641-1648.

25. Ragaz J, Jackson SM, Le N, Plenderleith IH, Spinelli JJ, Basco VE, Wilson KS, Knowling MA, Coppin CM, Paradis M, Coldman AJ, Olivotto IA: Adjuvant radiotherapy and chemotherapy in node-positive premenopausal women with breast cancer [see comments]. N Engl J Med 1997, 337:956-962.

26. Voogd AC, van Oost FJ, Rutgers EJ, Elkhuizen PH, van Geel AN, Scheijmans LJ, van der Sangen MJ, Botke G, Hoekstra CJ, Jobsen JJ, van de Velde CJ, von Meyenfeldt MF, Tabak JM, Peterse JL, van de Vijver MJ, Coebergh JW, van Tienhoven G: Long-term prognosis of patients with local recurrence after conservative surgery and radiotherapy for early breast cancer. Eur J Cancer 2005, 41:2637-2644.

27. Cajucom CC, Tsangaris TN, Nemoto T, Driscoll D, Penetrante RB, Holyoke ED: Results of salvage mastectomy for local recurrence after breast-conserving surgery without radiation therapy. Cancer 1993, 71:1774-1779

28. Shen J, Hunt KK, Mirza NQ, Buchholz TA, Babiera GV, Kuerer HM, Bedrosian I, Ross MI, Ames FC, Feig BW, Singletary SE, Cristofanilli M, MericBernstam F: Predictors of systemic recurrence and disease-specific survival after ipsilateral breast tumor recurrence. Cancer 2005, 104:479-490.

29. Kurtz JM, Amalric R, Brandone $H$, Ayme $Y$, Jacquemier J, Pietra JC, Hans $D$, Pollet JF, Bressac C, Spitalier JM: Local recurrence after breast-conserving surgery and radiotherapy frequency, time course, and prognosis. Cancer 1989, 63:1912-1917.

30. Fredriksson I, Liljegren G, Arnesson LG, Emdin SO, Palm-Sjövall M, Fornander T, Holmqvist M, Holmberg L, Frisell J: Local recurrence in the breast after conservative surgery-a study of prognosis and prognostic factors in 391 women. Eur J Cancer 2002, 38:1860-1870.

\section{Pre-publication history}

The pre-publication history for this paper can be accessed here: http://www.biomedcentral.com/1471-2407/10/479/prepub

doi:10.1186/1471-2407-10-479

Cite this article as: Chen et al:: Internal mammary lymph node recurrence: rare but characteristic metastasis site in breast cancer. $B M C$ Cancer 2010 10:479.

\section{Submit your next manuscript to BioMed Central and take full advantage of:}

- Convenient online submission

- Thorough peer review

- No space constraints or color figure charges

- Immediate publication on acceptance

- Inclusion in PubMed, CAS, Scopus and Google Scholar

- Research which is freely available for redistribution

Submit your manuscript at www.biomedcentral.com/submit
C) Biomed Central 